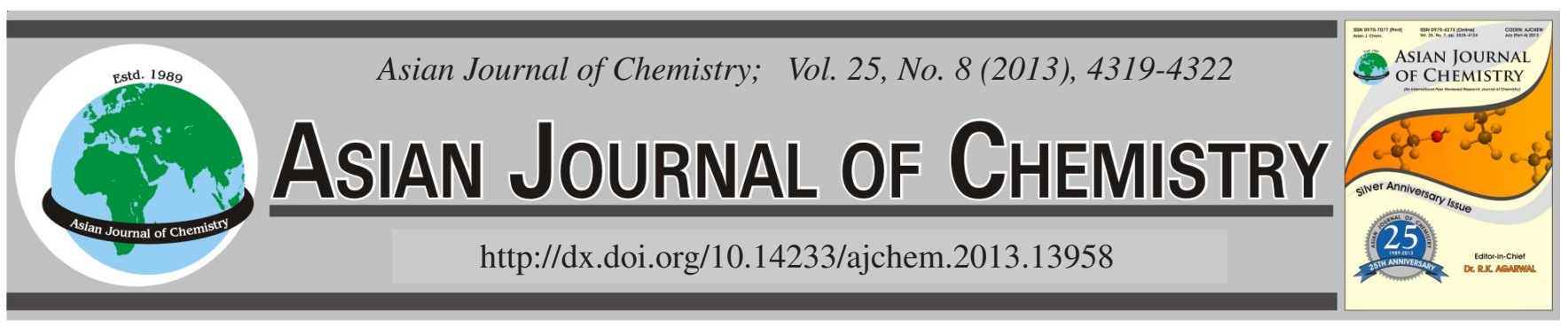

\title{
Adenosine 3',5'-Cyclic Monophosphate Extracted from Local Isolate of Bacillus Species
}

\author{
Tarik Mohammed Ali Rajab ${ }^{1}$, Gaylany H. Abdullah ${ }^{2}$, Hamid Ghaffoori Hasan ${ }^{1}$ and Abdul Amir H. Kadhum ${ }^{3, *}$
}

\author{
${ }^{1}$ Department of Chemistry, College of Education (Ibn AlHaitham), Baghdad University, Baghdad, Iraq \\ ${ }^{2}$ Department of Chemistry, Faculty of Science and Health, Koya University, Koysinjaq, Arbil, Iraq \\ ${ }^{3}$ Chemical and Process Engineering, Universiti Kebangsaan Malaysia, 43600 UKM, Bangi Selangor, Malaysia
}

*Corresponding author: E-mail: bilal.chem.82@gmail.com

(Received: 24 April 2012;

Accepted: 9 February 2013)

AJC-12954

Bacillus sp has been isolated locally from Sulaimani soil sample using nutrient agar plates. The isolate was identified as Bacillus genus
according to the morphological feature of the colonies and cells. The bacterial growth was obtained using nutrient broth at $37^{\circ} \mathrm{C}$ of $\mathrm{pH}$
7.2. Adenosine $3^{\prime}, 5^{\prime}$-cyclic monophosphate was extracted from the broth medium using incubation periods of $6,12,18$ and $24 \mathrm{~h}$. The
extract was purified using Dowex-50 H from column chromatography technique. The purified adenosine $3^{\prime}, 5^{\prime}$-cyclic monophosphate was |
identified using UV, HPLC and TLC analysis.
Key Words: Adenosine 3',5'-cyclic monophosphate, Bacteria, Bacillus species, Column chromatography.

\section{INTRODUCTION}

Adenosine 3',5'-cyclic monophosphate (cAMP) is essentially ubiquitous and it is found in animal cells ${ }^{1}$, plants $^{2}$, fungi ${ }^{3}$ and bacteria $^{4}$. In vertebrate, synthesis of cAMP is stimulated by peptide hormones interacting with protein receptors in the cell membrane. In higher cells, cAMP is degraded by cyclic nucleotide phosphodiesterases and intracellular level can decrease rapidly ${ }^{5}$. In enteric coliforms the intracellular concentration of cAMP is rigorously controlled ${ }^{6}$. Adenylate cyclase activity is controlled through a mechanism that senses environmental conditions. This signal is mediated by transport proteins located in the cell membrane. The nucleotide is degraded by cAMP phsphodiesterase; it is also readily excreted ${ }^{7}$. The most familiar role for cAMP in vertebrates is in the regulation of glycogen and triglyceride metabolism ${ }^{1}$. cAMP in bacteria functions not as an activator of the protein kinase ${ }^{8}$, but rather as an activator of CRP, an allosteric DNA-regulatory protein ${ }^{9,10}$ that modulates the transcription of several genes ${ }^{4}$ and function most dramatically to regulate the expression of inducible catabolic operons. In normal situations, some cAMP is always present; even cells grown in the presence of glucose produce detectable levels of the nucleotide ${ }^{11}$. Cyclic nucleotides have been detected in a variety of bacteria ${ }^{12}$. The effect of exogenous cAMP is not always unequivocal proof of a role for the nucleotide. It usually takes high concentration of the nucleotide, three orders of magnitude greater than that found in any cells, to have any effect. The effect could be a nonspecific to the nucleotide ${ }^{4}$. It should be noted that cAMP has been found in B. subtilis $^{13}$. A report definitively shows that cAMP is made in appreciable quantities when cells are grown with limiting oxygen $^{14,15}$. There is another report showing that cAMP is not found in Clostridium perfringens ${ }^{16}$. Table-1 lists some bacteria in which cyclic nucleotides have been found ${ }^{4}$.

Criteria: A, glucose-mediated repression of enzyme synthesis; B, cAMP-mediated stimulatory effects; C, cyclic nucleotide measurement; D, genetic evidence, apparent cya and crp mutants; E, effects of in vitro gene expression; TCA, tricarboxylic acid.

The present study represents first investigation of adenosine 3',5'-cyclic monophosphate from local isolate of Bacillus sp using nutrient broth medium. Also, in the present work, initially an attempt was made to partially purify the cAMP present in the culture filtrate obtained from fermentation action by Bacillus sp. UV, HPLC and TLC analysis were done to obtain additional data towards understanding its properties.

\section{EXPERIMENTAL}

Isolation and identification: The simplest technique that enriches for aerobic spore formers was used ${ }^{17}$. Different soil samples were dried in an oven at $50^{\circ} \mathrm{C}$ for overnight; a diluted soil sample was pasteurized at $80^{\circ} \mathrm{C}$ for $15 \mathrm{~min}$ and then plated onto nutrient agar plates. The plates were incubated at $37^{\circ} \mathrm{C}$ for $24 \mathrm{~h}$ and up to several days. The plates were examined after $24 \mathrm{~h}$ for typical Bacillus colonies identified as catalasepositive, gram-positive, endospore-forming $\operatorname{rods}{ }^{17,18}$. 


\begin{tabular}{llc}
\hline \multicolumn{3}{c}{ REPORTS OF CYCLIC NUCLEOTIDES } \\
IN MISCELLANEOUS BACTERIA \\
\hline \multicolumn{1}{c}{ Microorganism } & \multicolumn{1}{c}{ Property } & Criteria \\
\hline Aeromonas spp & $\begin{array}{l}\text { "Suicide" growth on } \\
\text { glucose }\end{array}$ & A, B \\
Archaebacteria & Measurable cAMP & C \\
Arthrobacter oxidans & Glucose repression of 6- & A \\
Bacillus circulans & hydroxynicotine oxidase & \\
Bacillus subtilis & B-Xylanase expression & B \\
& cGMP and sporulation & B \\
Chlamydia trachomatis & measurable cAMP in O2- & C \\
Erwinia chrysanthemi & limited cells & \\
Klebsiella aerogenes & Pevelopment & B \\
Klebsiella pneumoniae & hut operons induction & TCA cycle enzymes \\
Legionella pneumophila & Nitrogen metabolism & A, B B \\
Mycobacterium smegmatis & Fatty acid synthesis & A, B \\
Mycoplasma pneumoniae & Glass attachment & B \\
Pseudomonas fluorescens & Antibiotic production & B \\
Vibrio cholera & - & A, B \\
Vibrio fischeri & Bioluminescence & B, B, D \\
Vibrio parahaemolyticus & Protease production & D \\
Marine microorganisms & cAMP uptake & C \\
\hline & &
\end{tabular}

Extraction of cAMP from culture broth: Nutrient broth in $250 \mathrm{~mL}$ flasks were used for detecting cAMP. The flasks were inoculated with $1 \mathrm{~mL} /$ flask from local isolate of Bacillus $s p$, in which it contain $11 \times 10^{7}$ cell $/ \mathrm{mL}$, then the flasks were incubated at $37^{\circ} \mathrm{C}$ for different incubation times $(6,12,18$ and $24 \mathrm{~h}$ ). The broth culture after each incubation time was centrifuged in (NUVE NF 615) at $5000 \mathrm{rpm}$ for $15 \mathrm{~min}$. A protocol of Brooker ${ }^{19}$ was adopted so that cAMP was isolated in the supernatant. The procedure was used by taking $3 \mathrm{~mL}$ of centrifuged broth sample to the test tube and then addition of $0.4 \mathrm{~mL}$ of $5 \% \mathrm{ZnSO}_{4}$ ( $5 \mathrm{~g}$ of zinc sulphate dissolved in 100 $\mathrm{mL}$ distilled water) was followed, then $0.4 \mathrm{~mL}$ of $0.3 \mathrm{~N}$ $\mathrm{Ba}(\mathrm{OH})_{2}(4.725 \mathrm{~g}$ of dissolved in $100 \mathrm{~mL}$ distilled water) was added. Mixed well and then centrifuged for $10 \mathrm{~min}$ at the 3000 $\mathrm{rpm}$, this would precipitate protein, phosphates, pyrophosphates and all nucleotides except cAMP ${ }^{19-21}$.

Column chromatography purification: The technique was used to purify the extracted cAMP; a volume of $3 \mathrm{~mL}$ of the supernatant (containing cAMP) from step 2 was loaded on a Dowex 50W hydrogen form of the dimension $(1 \mathrm{~cm} \times 5$ $\mathrm{cm}$ ) and elutated with distilled water at flow rate of $3 \mathrm{~mL} / \mathrm{min}$. The eluted fractions of $3 \mathrm{~mL}$ were collected ${ }^{21}$ (Fig. 1). After the collection of 15 fractions, it was found that fraction No. 2 contains the highest activity of the purified cAMP as shown in the Fig. 1. Same results were obtained in which fraction No. 2 represents the activity of the purified cAMP peak.

UV analysis of CAMP: $c A M P$ has a strong characteristic UV spectrum with a maximum $\lambda$ at $258 \mathrm{~nm}$ at $\mathrm{pH} 7$.

To prepare standard solution, $c a .1 \mathrm{mg}$ of cAMP was dissolved in $25 \mathrm{~mL}$ distilled water, the $\mathrm{pH}$ was adjusted to 7 , where $3 \mathrm{~mL}$ of cuvette has been used as a sample container and after the appropriate dilution, scanned the absorbance using (Helios alpha type) ultraviolet spectrophotometer ${ }^{22}$.

Absorption at neutral pH: After neutralization the standard solution, $3 \mathrm{~mL}$ of the standard cAMP solution was

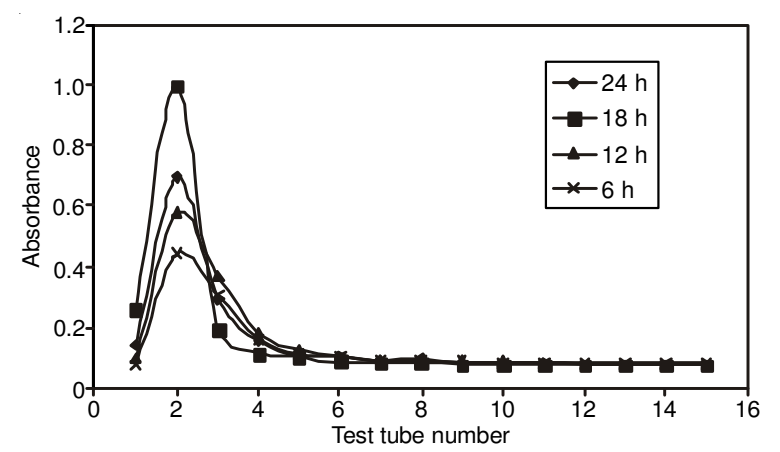

Fig. 1. Column purification of extracted cAMP from Bacillus $S$. at different time using Dowex $50 \mathrm{w}(1 \mathrm{~cm} \times 5 \mathrm{~cm})$ colum

scanned by spectrophotometer between $220-300 \mathrm{~nm}$. A maximum absorbance at $258 \mathrm{~nm}$ was obtained. The same protocol was applied for extracts of cAMP. In which fraction No. 2 contained separated and purified cAMP and reflected a sharp peaks at $\lambda=258 \mathrm{~nm}^{23}$ (Fig. 2).

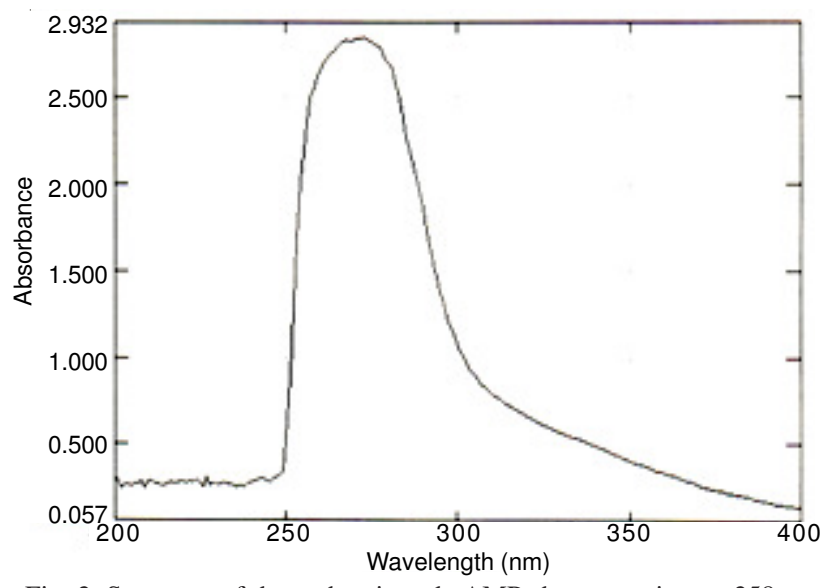

Fig. 2. Spectrum of the authenticated cAMP shows maxima at $258 \mathrm{~nm}$

Absorption at acidic and basic pH: Three $\mathrm{mL}$ of standard cAMP solution and same volumes of extracted cAMP acidified at $\mathrm{pH}=2$ by the addition of $1 \mathrm{~N} \mathrm{HCl}$. These fractions were scanned using spectrophotometer between 220-300 nm. Maximum absorbance was obtained at the wave length of $256 \mathrm{~nm}$ (Fig. 3). Same protocol was used but the fractions were made basic at $\mathrm{pH}=12$ using $1 \mathrm{~N} \mathrm{NaOH}$ and scanned using spectrophotometer between the 220-300 $\mathrm{nm}$. Maximum absorbance was obtained at wavelength of $260 \mathrm{~nm}$ (Fig. 4) ${ }^{23,24}$.

HPLC analysis: HPLC 10AVP consist of two deliver pumps, 10 AVP controller, the injection was Reodyne 7125 USA, the eluted chromatogram was monitored by UV-VIS 10 AV-SPD Detector. The separation was performed on a reversed phase $(250 \mathrm{~mm} \times 4.6 \mathrm{~mm}$ h.d). Column $5 \mu \mathrm{m}$ particle size, type DB-C ${ }_{18}$. Mobile phase: methanol: water 50/50 (v/v). Flow rate: $1 \mathrm{~mL} / \mathrm{min}$. Temperature: $25^{\circ} \mathrm{C}$. Detection: UV set at 260 nm. Firstly $5 \mu \mathrm{L}$ of mobile phase without standard and samples was injected to comparing with another chart. The standard was tested by taking $1 \mathrm{~mL}$ of standard and added to $1 \mathrm{~mL}$ of mobile phase. After mixing in vortex, $5 \mu \mathrm{L}$ was injected into HPLC and by the detector recording the chromatogram chart and measuring the retention time. Same technique was used for determination the retention time of the purified cAMP eluted peak (step 3) ${ }^{25,26}$. 


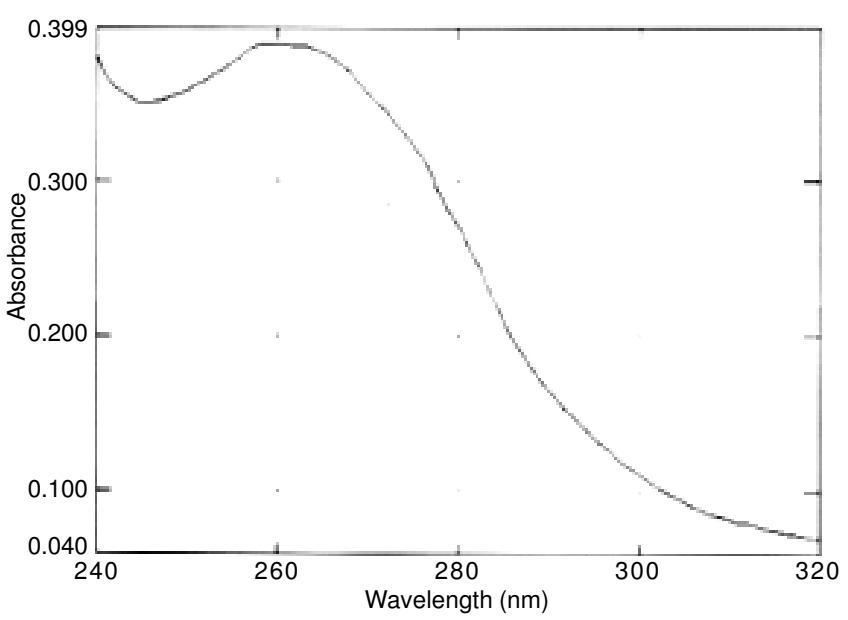

Fig. 3. UV Spectrum of the extracted cAMP at $256 \mathrm{~nm}$ using acidic medium

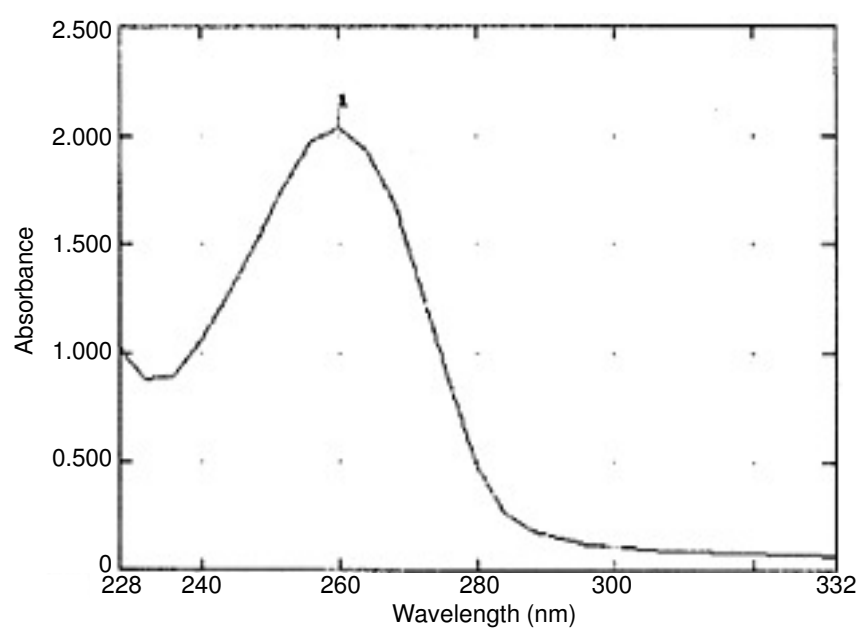

Fig. 4. UV Spectrum of the extracted cAMP a $260 \mathrm{~nm}$ using basic medium

TLC analysis: A uniform thin layer silica gel G60 has been used as the stationary phase in the project to separated cAMP. Silica gel G60 was mounted at the thickness of 300 $\mu \mathrm{m}$ on the glass plate and the area of $(20 \mathrm{~cm} \times 20 \mathrm{~cm})$. The silica gel $\mathrm{G} 60$ plate was kept at $100{ }^{\circ} \mathrm{C}$ for $1 \mathrm{~h}$ for reactivation before the application of samples.

Sample preparation: The extracted cAMP (fraction 2) was evaporated to dryness under vacuum at $55^{\circ} \mathrm{C}$ and cooled after dryness then mixed with $20 \mu \mathrm{L}$ distilled water ${ }^{25}$.

Sample application: A micropipette was used for applying spotting $2(\mathrm{~cm})$ from the edge of the plate. Typical spot sizes were $5 \mu \mathrm{L}$. Drying of the spots was achieved using an air blower; more samples were then applied if necessary.

Plate development: Development of the plate was achieved in a glass tank in which the inside wall has been covered by filter-paper (Whatman No. 1) in order to ensure equilibration after saturation of the atmosphere within the tank by the solvent vapour. Developing solvent was added to a depth of $c a .1 .5 \mathrm{~cm}$ of the tank. The tank top was covered to reach the equilibrium within $1 \mathrm{~h}$ and the plate was then placed vertically in the tank.

Spot detection: Ultraviolet light absorbing spots were visualized by spraying with $0.01 \%$ ethanolic solution of 2,7dichlorofluresceine; this was used for nucleotides, cyclic nucleotides which appeared as dark areas on a fluorescent background. Several solvent systems were used, but $n$-butanol: glacial acetic acid:distilled water; 2:5:3 (v/v) was the major system used as previously suggested ${ }^{27,28}$. The $R_{\mathrm{f}}$ values for the standard and the purified cAMP were recorded and given in Table-1.

\section{RESULTS AND DISCUSSION}

Identification of cAMP using UV analysis: Fig. 1 shows the purification scheme analysis of cAMP peak from different time of incubation. Incubation for $18 \mathrm{~h}$ reflects the highest activity of cAMP. It is known that cyclic adenosine 3',5'-nucleotides contains hetero nitrogenous bases and the basic principle of UV analysis for such type of compounds depends on the presence of such nitrogenous bases ${ }^{29,30}$. As cAMP and other derivatives contain an adenosine base which is a conjugated ring system, these compound have a strange characteristic UV spectrum with a maximum wavelength of $258 \mathrm{~nm}$ at $\mathrm{pH} 7.0$ (Fig. 2) ${ }^{30}$. The UV analysis of the purified cAMP from Bacillus $S$. was performed at different $\mathrm{pH}$ values as shown in Figs. 3 and 4. Shifting in the wavelength of the peak absorbance has been occurs. Regular use of this property was made in identification and quantification. These results were similar to those previously described ${ }^{23}$ in which cAMP fractions were purified from different tissues. The UV spectrum of the Basillus $S$. was compared with the spectra of the standerd cAMP. This is in consistence with the findings of Krstulovic et al. ${ }^{28}$. No interferences were seen from other naturally occurring constituents in the gradients elution separation of the cAMP extract. The analysis does not require any pre-concentration and its sensitivity is of considerable importance in analyzing limited amounts of samples for the exceedingly low concentration of this compound. The alternative isocratic elution mode optimized for the selective analysis of cAMP, offers a rapid and reliable method for determination of this important compound in biological samples. The method of analysis employed in this study lend themselves easily to several simple identification methods, which are necessary if the identity of the components of complex mixtures of biological compounds is to be determined valuably and unambiguously. This method coupled with an appropriate sample preparation can be used for biological samples of different origin.

Identification of CAMP using TLC analysis: Thin layer chromatography analysis has been routinely used for the analysis and identification of cAMP and its derivative, in which the $R_{f}$ values used for comparison between standard and extracted Basillus S. cAMP (Table-2). The chances that chromatographic peak is a compound other than cAMP seem remote. Bases or nucleosides would be eliminated by the other extractions. The zinc-barium precipitation, the Dowex-50W column and by thin layer chromatography were used for this purpose. Similar results were reported by Kuo et al. ${ }^{31}$ and Brooker ${ }^{25}$.

TABLE-2

TLC-ANALYSIS FOR STANDARD CAMP AND NORMAL AND LEUKAEMIC URINAY CAMP

$\begin{array}{lc}\text { Parameter } & \mathrm{R}_{\mathrm{f}} \text { Value } \\ \text { St. CAMP } & 0.44 \\ \text { UN. CAMP } & 0.43 \\ \text { UL. CAMP } & 0.45\end{array}$


Identification of cAMP using HPLC technique: High performance liquid chromatography is the most versatile and widely used type of elution chromatography, the technique is used by chemists to separate and determine a variety of organic, inorganic and biological materials ${ }^{30}$. The values of retention time $3.02 \mathrm{~min}$, confirm the successful extraction of both standard and purified cAMP extracted from Bacillus $S$. Fig. 5. The retention times obtained in this study differed from that previously reported by Newton ${ }^{24}$, Brooker ${ }^{25}$ and Krustolovic ${ }^{28}$, whose findings also show different retention times. These variations can be explained by differences in the type of HPLC model, length of column, types of mobile phase and its flow rates and the type of packed column material ${ }^{32}$. Data obtained from the three techniques used for the analysis and identification of cAMP provide strong evidence for the similarity between the standard and extracted cAMP, despite slight differences between them, which we believe may be due to differences in purity, sensitivity of the instruments and methods used.

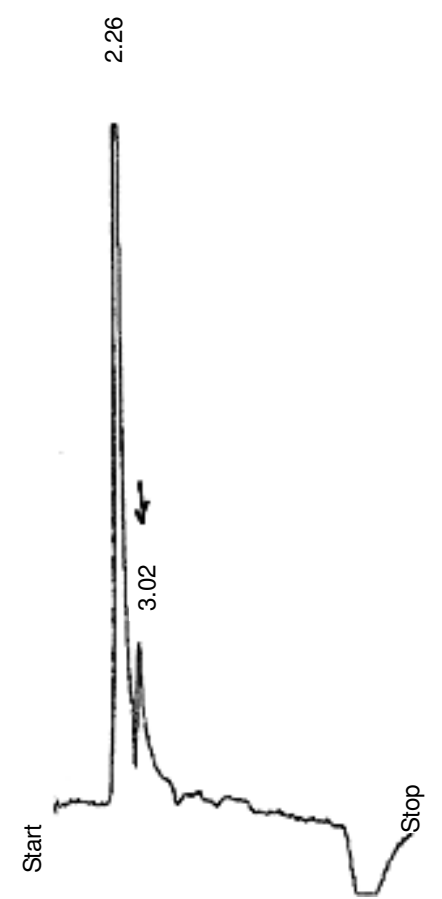

Fig. 5. HPLC analysis for cAMP peak from isolated Bacillus species

\section{Conclusion}

It seems that cAMP signaling is involved in most aspects of differentiation and maturation of cells. As it was recognized that cAMP has a significant role in the regulation of carbohydrates and lipids regulation through gene regulation mostly involved in energy metabolism. Thus, cAMP can be play a significant role in causing a conformational changes in cell through its cAMP receptor protein. Thus, the aim of this study was focused on the bacteria cell growth secretion of cAMP in a simple assay. The advantages of the procedure described above seems significant. The sensitivity of the assay is high and the actual assay is simple to perform.

\section{REFERENCES}

1. E.W. Sutherland, I. Oye and R.W. Butcher, Recent Prog. Horm. Res., 12, 623 (1965).

2. N. Armhein, Ann. Rev. Plant Physiol., 28, 123 (1977).

3. D.L. Robertson, M.T. Tippetts and S.H. Leppla, Gene, 73, 63 (1988).

4. J.L. Botsford and J.C. Harman, Microbiol. Rev., 56, 100 (1992).

5. B. Crombrugghe, S. Busby and H. Buc, Science, 224, 831 (1984).

6. B.J. Bachmann, Microbiol. Rev., 54, 130 (1990).

7. S. Busby and H. Buc, Microbiol. Sci., 4, 371 (1987).

8. A.J. Cozzone, Ann. Rev. Microbiol., 42, 97 (1988).

9. Bacteria (eubacteria), Taxonomy Browser, NCBI, Retrieved (2008).

10. M.C. Hogan, In eds.: S. Draggan and C.J. Cleveland, Bacteria, Encyclopedia of Earth, National Council for science and the Environment, Washington DC (2010).

11. M. Stapleton, I. Hug, P. Hunt, K. Arving, J.A. Peter, R. Buxton and J. Green, J. Biol. Chem., 285, 7016 (2010).

12. S. Guan, W. Wang, J. Lu, W. Qian, G. Huang, X. Deng and X. Wang, Molecules, 16, 3371 (2011).

13. J.L. Bostford, Microbiol. Rev., 45, 620 (1981).

14. T.M. Lau and K.Y. Chean, Microbios., 39, 137 (1984).

15. H. Mach, M. Hecken and F. Mach, FEMS Microbiol. Lett., 22, 27 (1984).

16. P. Setlow and L.E. Sacks, Can. J. Microbiol., 29, 1228 (1983).

17. K. Todar, The genus Bacillus. In: Todar's Online Textbook of Bacteriology, Retrieved 5 June 2005, from http://www.textbookofbacteriology.net (2005).

18. J.W. Shaw, S.B. Oldham, L. Rosoff, J.E. Bethune and M.P. Fichman, J. Clin. Invest., 59, 14 (1977).

19. G. Brooker, Method Biochem. Anal., 22, 95 (1974).

20. L.R. Chase, G.L. Melson and G.D. Aurbach, J. Clin. Invest., 48, 183 (1969).

21. Y.H. Abdulla and K. Hamadah, Lancet, 21, 378 (1970).

22. A.L. Mohamad, M.Sc. Thesis, College of Science, Mosul University, Mosul, Iraq (2009).

23. S. Budavari, The Merck Index, An Encyclopedia of Chemicals and biologiucals, Merck \& Co. In, edn. 11, p. 2718 (2003).

24. R.P. Newton, D. Chiatamte, D. Ghosh, A.G. Brown, T.J. Walton, F.M. Harris and E.G. Brown, Phytochemistry, 28, 2243 (1989).

25. G.J. Brooker, Biol. Chem., 246, 7810 (1971).

26. C.J. Smith, J.P. Little and M.J. Milton, Biochem. Soc. Trans., 17, 199 (1989).

27. G.D. Aurbach, J.T. Aurbach, L.R. Chase and G.L. Melson, Ann. Intern. Med., 70, 1243 (1969).

28. A.M. Krstulovic, R.A. Harrtwick and P.R. Brown, Clin. Chem., 25, 235 (1979).

29. H.G. Hassan, Ph.D. Thesis, University of Wales, UK (1990).

30. G.A. Robinson, R.W. Butchert and E.W. Sutherland, Eds. cAMP Publ. Academic Press. NY. And London, pp. 150-151 (1971).

31. J.F. Kuo and P. Greengard, Adv. Cyclic Nucleotide Res., 2, 41 (1972).

32. D.A. Skooge, D.M. West, F.J. Holler and S.R. Crouch, In: Fundamentals of Analytical Chemistry, NY, edn. 8, p. 973 (2004). 